\title{
The Effects of Posterior Talar Glide and Dorsiflexion of the Ankle Plus Mobilization with Movement on Balance and Gait Function in Patient with Chronic Stroke: A Randomized Controlled Trial
}

Sang-Lim Kim, Byoung-Hee Lee ${ }^{l}$

Department of Physical

Therapy, Graduate School of

Physical Therapy, Sahmyook

University, ${ }^{1}$ Department

of Physical Therapy,

Sahmyook University, Seoul, Republic of Korea
Background: This study was to evaluate the effects of weight-bearing-based mobilization with movement (WBBMWM) on balance and gait in stroke patients. Methods: Thirty stroke patients participated in this study. All individuals were randomly assigned to either WBMWM group $(n=15)$ or weight-bearing with placebo mobilization with movement group (control, $n=15$ ). Individuals in the WBMWM group were trained for 10 glides of 5 sets a day, 5 times a week during 4 weeks. Furthermore, individuals in the control group were trained for 10 lunges of 5 sets a day, 5 times a week during 4 weeks. All individuals were measured weight-bearing lunge test (WBLT), static balance ability, timed up and go test (TUG), and dynamic gait index (DGI) in before and after intervention. Results: The result showed that WBBMWM group and control group had significantly increased in WBLT, postural sway speed, total postural sway path length with eyes open and closed, TUG and DGI $(P<0.05)$. In particular, the WBMWM group showed significantly greater improvement than control group in WBLT, static balance measures, TUG, and DGI $(P<0.05)$. Conclusion: Therefore, WBMWM improved ankle range of motion, balance, and gait in stroke patients. These results suggest that WBBMWM is feasible and suitable for individuals with a stroke.

KEYWORDS: Balance, gait, mobilization with movement, stroke

\section{INTRODUCTION}

ctroke is a disease involving disability caused by $\circlearrowleft$ blockage of blood flow of cerebral vessel due to cerebrovascular, cardiac diseases, or cerebral tissue hemorrhage ${ }^{[1]}$ and shows motor, cognitive, sensation, and speech dysfunction depending on the lesion site. ${ }^{[2]}$ Among them, motor dysfunctions are skeletal muscle paralysis, spasticity like abnormal muscle tone, movement pattern, postural and equilibrium defect, and weight-shifting ability decrease, and these are caused by motor control ability malfunction. ${ }^{[3]}$

Ankle spasticity of stoke patient stiffens ankle joint by shortening plantar flexor and causes joint range of motion (ROM) decrease, joint movement resistance increase, and passive joint movement decrease to limit ankle joint movement. ${ }^{[4]}$ Due to ankle movement

\section{Access this article online}

\begin{tabular}{ll}
\hline Quick Response Code: & Website: \\
& \\
& \\
&
\end{tabular}

limitation, weight-bearing of nonparalytic side increase, weight-shifting stability decrease, and postural sway increase as twice as much compared to normal. ${ }^{[5]}$ Furthermore, decreased stable weight shift brings about not only loss of static balance but also dynamic balance problem and causes secondary problem such as fall. ${ }^{[6]}$ Ankle joint movement controls effect of foot on ground to maintain gait and balance; ${ }^{[7]}$ compensation is provoked during gait by balance problem, consequently consume much more energy than normal and become abnormal gait. ${ }^{[8]}$ These balance and gait ability decrease of stroke act as instrumental activities of daily living factors to

Address for correspondence: Prof. Byoung-Hee Lee, Department of Physical Therapy, Sahmyook University, Hwarangro-815, Nowon-gu, Seoul, 01795, Republic of Korea.

E-mail: 3679@syu.ac.kr

This is an open access article distributed under the terms of the Creative Commons Attribution-NonCommercial-ShareAlike 3.0 License, which allows others to remix, tweak, and build upon the work non-commercially, as long as the author is credited and the new creations are licensed under the identical terms.

For reprints contact: reprints@medknow.com

How to cite this article: Kim SL, Lee BH. The effects of posterior talar glide and dorsiflexion of the ankle plus mobilization with movement on balance and gait function in patient with chronic stroke: A Randomized controlled trial. J Neurosci Rural Pract 2018;9:61-7. 
decrease independence as a result brings participation restriction on local community. ${ }^{[9]}$

To increase ankle function of stroke patient, ankle muscle strength training, functional electrical stimulation training, ${ }^{[10]}$ elasticity band orthosis training, ${ }^{[1]]}$ proprioceptive control training, ${ }^{[12]}$ and joint mobilization ${ }^{[13]}$ are being conducted recently. Among those methods, joint mobilization helps regain motion-limited joints to increase ROM and it is usually applied for limited range of motion from musculoskeletal reasons. ${ }^{[14]}$ However, application of joint mobilization on ankle of stoke patient increased ankle ROM and reduced required time for sit to stand; therefore, it was effective. ${ }^{[13]}$

Mulligan $^{[15]}$ modified joint mobilization for improvement of ankle joint movement and suggested weight-bearing-based mobilization with movement (WBBMWM); application of the mobilization on ankle sprain patient was effective on ankle $R O M{ }^{[16]}$ ROM sustainment time, ${ }^{[17]}$ and single support time ${ }^{[18]}$ during gait improvement.

However, only a few studies for clinical effects of WBBMWM have been reported. Therefore, the purpose of this study was to observe the effects of posterior talar glide, dorsiflexion of the ankle, mobilization with movement (MWM) on ROM of ankle joint, balance, and gait function in patients with chronic stroke.

\section{Methods}

\section{Participants}

Forty patients with first-time stroke were recruited for this study, which was conducted at M hospital in Seoul. Inclusion criteria were as follows: (1) hemiplegia patients over 6 months after stroke, (2) independent ambulation of more than 10 meters without an assistive device, 3) Mini-Mental State Examination-Korean (MMSE-K) of more than 24 points, (4) weight-bearing lunge test (WBLT) of $<10 \mathrm{~cm}$, and (5) motor recovery of the paretic lower limb in Brünnstrom stage of 2-4. The exclusion criteria were hypermobility on ankle joint, orthopedic disease such as fracture and osteoporosis, or a visual field defect. All participants were examined to investigate characteristics regarding their medical history and orthopedic or neurological status. After checking the selection criteria by a blinded clinical researcher, seven patients were not included because they did not satisfy the selection criteria (MMSE-K of $<24$ points, $n=4$; visual field defect, $n=3$ ).

This study was conducted using a pre- and post-test design with a single-blind randomized control trail. Clinical measures were assessed at baseline and at a 4-week reassessment. The present study was approved by MyoungJi ChoonHey Hospital Institutional Review Board (MJCHIRB-2015-01), and the objective of the study and its requirements were explained to the individuals, and all participants provided written parental consent; thus, the rights of human subjects were protected.

\section{Experimental procedures}

Before starting the experiment, all participants received an examination in order to investigate characteristics regarding history and orthopedic or neurological examination. One hour before the start of the intervention, the individuals were randomly assigned into two groups: WBBMWM group $(n=17)$ and weight-bearing with placebo MWM group (control, $n=16$ ). Group assignment was placed in envelopes and sealed. Each individual who agreed to enter the study randomly selected an envelope with the group assignment enclosed.

Participants in the WBBMWM group received posterior talar glide and dorsiflexion of the ankle joint plus WBMWM for 10 glides of 5 sets a day, 5 times a week during 4 weeks and included rest periods as needed. The control group received weight-bearing with placebo MWM for 10 lunges of 5 sets a day, 5 times a week during 4 weeks. Two participants in the WBBMWM group and one participant in the control group withdrew during the process of study due to discharge.

\section{Intervention}

WBMWM was applied in standing posture with affected lower extremity positioned on $20 \mathrm{~cm}$ footplate; thereafter, patients are to actively move center of mass to affected side and make knee flexion and ankle dorsiflexion and at the same time, therapists are to stabilize the ankle bone, hang therapeutic belt on distal tibia, and glide it back. For improvement of joint mobilization, gliding was applied with Grade III. ${ }^{[19]}$ (WBBMWM) is composed of warm-up, main, and cool-down exercise. As warm up and cool down, before and after the experiment, three cycles of weight-bearing exercise was executed. Main exercise was conducted through $10 \mathrm{~s}$ of WBBMWM, $10 \mathrm{~s}$ of resting period in starting position, 10 repetition, total of 5 sets. ${ }^{[20,21]}$ Each set includes 2 min break. ${ }^{[16]} \mathrm{A}$ towel was attached to achilles hill to reduce the risk of skin damage. ${ }^{[17]}$ To reduce the risk of fall during training, assist table was located, just in case 1 physical therapist was assisting from the sideline.

For control group, WBBMWM was applied in standing posture with affected lower extremity positioned on $20 \mathrm{~cm}$ footplate; thereafter, patients are to actively move center of mass to affected side and make knee flexion 
and ankle dorsiflexion and at the same time, therapists are to stabilize the ankle bone, hang therapeutic belt on distal tibia but not gliding it back for placebo effect. ${ }^{[17,20]}$ As warm up and cool down, before and after the experiment, three cycles of weight-bearing exercise were executed. Main exercise was conducted through $10 \mathrm{~s}$ of WBBMWM, $10 \mathrm{~s}$ of resting period in starting position, 10 repetition, and total of 5 sets. ${ }^{[20,21]}$ Each set includes 2 min break. ${ }^{[16]} \mathrm{A}$ towel was attached to achilles hill to reduce the risk of skin damage. ${ }^{[17]}$ To reduce the risk of fall during training, assist table was located, just in case 1 physical therapist was assisting from the sideline.

All participants were offered usual physical therapy for 30-min sessions per day, 5 days per week for 4 weeks. General physical therapy exercise program was conducted by a physical therapist, consisting of neurodevelopmental treatment, proprioceptive neuromuscular facilitation, and Bobath approach.

\section{Outcome measurement}

In this study, WBLT was conducted to measure ankle joint ROM. ${ }^{[20-22]}$ Second toe and center of the heel were matched up; heel was on the ground over the wall, and knee was attached vertically. The distance between the second toe and the wall was recorded to measure the ankle dorsiflexion indirectly. ${ }^{[20]}$ Interrater reliability was $r=0.97-0.98$ and intrarater reliability was $r=0.97-$ 0.99 ; therefore, reliability was high. ${ }^{[23]}$ To minimize the error of measurement, one examiner and one assistance had examination before and after the training, average of 3 repetition was used in the study.

Static balance ability was assessed according to the postural sway path length and speed at the center of pressure (COP) by using the Balancia software system connected to a computer, through a Wii balance force platform with 4 load cells. To measure static balance, the individuals were asked to place their feet on a Wii Fit $^{\mathrm{TM}}$ balance board with their feet spread apart at shoulder width. The individuals were then asked to maintain their balance for $30 \mathrm{~s}$ while looking at a point on a wall $3 \mathrm{~m}$ away. Static balance ability was measured by the postural sway path length and speed at the COP using the Balancia software. ${ }^{[24]}$

Individuals performed the timed up and go test (TUG) before and after 4 weeks of intervention. TUG test was used for testing of dynamic balance ability. It was the time that a person took to rise from a chair, walk 3 $\mathrm{m}$, turn around, walk back to the chair, and sit down. During the test, the person was expected to wear their regular footwear and use any mobility aids that they would normally require. ${ }^{[25]}$ Research has shown the TUG has excellent interrater (intraclass correlation coefficient, $\mathrm{ICC}=0.98)$ and intrarater reliability $(\mathrm{ICC}=0.99)$. Mean value after measuring three times with a stopwatch was recorded, and participants rested for 2 min between trials. During the test, participants were expected to wear their regular footwear and did not use any mobility aids.

This study used dynamic gait index (DGI) for measurement of functional gait ability needed for gait. DGI consists of 8 items and it is as in the following: gait level surface, change in gait speed, gait with horizontal head turns, gait with vertical head turns, gait and pivot turn, step over obstacle, step around obstacles, and steps. DGI is a four-point ordinal scale, ranging from 0 to 3 , " 0 " indicates the lowest level of function and " 3 " the highest level of function, total of 24 point. In this study, to minimize measurement error, one examiner and one assistance had examination before and after the training, average of 3 repetitions was used in the study.

\section{Statistical analysis}

All statistical analyses were performed using SPSS 19.0 (SPSS Inc., Chicago, U.S.A.). The KolmogorovSmirnov test for normality was used. Chi-square test was used for binary variables, and Independent $t$-test was used for homogeneity testing among the two groups. Paired sample $t$-test was used for assessment of differences between pre- and post-testing sessions within group, and the independent $t$-test was used to compare the difference in WBLT, TUG, static balance ability, and DGI before and after training between groups. $P<0.05$ was considered statistically significant.

\section{RESULTS}

General characteristics of the remaining 30 participants with stroke who fulfilled the inclusion criteria for the study are summarized in Table 1. As shown in Table 1, Chi-square's results had no difference between WBBMWM and control group.

The WBBMWM group showed a significant improvement in the WBLT, which increased from $3.20 \mathrm{~cm}$ before training to $5.80 \mathrm{~cm}$ after training $(P=0.000)$, a significant improvement in TUG, which decreased from $27.15 \mathrm{~s}$ before training to $21.78 \mathrm{~s}$ after training $(P=0.000)$, and a significant improvement in DGI, which increased from 15.40 score before training to 19.13 score after training $(P=0.000)$.

Moreover, the control group demonstrated significant improvement in the WBLT, which increased from $2.93 \mathrm{~cm}$ before training to $3.80 \mathrm{~cm}$ after training $(P=0.01)$, a significant improvement in TUG, which decreased from $24.60 \mathrm{~s}$ before training 
to $22.01 \mathrm{~s}$ after training $(P=0.002)$, and a significant improvement in DGI, which increased from 17.20 score before training to 19.40 score after training $(P=0.000)$. The WBBMWM group showed significantly greater improvements in WBLT, TUG, and DGI $(P<0.05)$ compared to the control group, which suggests that the WBBMWM techniques improves the ROM of ankle joint, balance, and gait function in patients recovering from stroke [Table 2].

The WBBMWM group showed a significant improvement in the postural sway path length with eyes open at the COP, which decreased from $43.42 \mathrm{~cm}$ before training to $37.71 \mathrm{~cm}$ after training $(P=0.000)$, a significant improvement in the postural sway speed with eyes open, which decreased from $2.89 \mathrm{~cm} / \mathrm{s}$ before training to $2.51 \mathrm{~cm} / \mathrm{s}$ after training $(P=0.000)$, a significant improvement in the postural sway path length with eyes closed, which decrease from $54.40 \mathrm{~cm}$ before training to $46.66 \mathrm{~cm}$ after training $(P=0.000)$, a significant improvement in the postural sway speed with eyes closed, which increased from $3.62 \mathrm{~cm} / \mathrm{s}$ before training to $3.11 \mathrm{~cm} / \mathrm{s}$ after training $(P=0.000)$. Moreover, the control group demonstrated significant improvement in the postural sway path length with eyes opened, which decreased from $41.47 \mathrm{~cm}$ to $38.46 \mathrm{~cm}$ after training $(P=0.003)$, a significant improvement in the postural sway speed with eyes open, which decreased from $2.74 \mathrm{~cm} / \mathrm{s}$ to $2.56 \mathrm{~cm} / \mathrm{s}$ after training $(P=0.000)$, a significant improvement in the postural sway path length with eyes closed, which decrease from $46.21 \mathrm{~cm}$ to $43.90 \mathrm{~cm}$ after training $(P=0.013)$, and a significant improvement in the postural sway speed with

\begin{tabular}{|c|c|c|c|c|}
\hline \multicolumn{5}{|c|}{ Table 1: Demographic data of groups $(n=30)$} \\
\hline & WBBMWM $(n=15)$ & Control $(n=15)$ & $t / \chi^{2}$ & $P$ \\
\hline Age (year), mean \pm SD & $42.47 \pm 9.76$ & $51.40 \pm 14.38$ & -1.990 & NS \\
\hline \multicolumn{5}{|l|}{ Gender, $n(\%)$} \\
\hline Male & $9(60.0)$ & $9(60.0)$ & 0.000 & NS \\
\hline Female & $6(40.0)$ & $6(40.0)$ & & \\
\hline \multicolumn{5}{|l|}{ Side of hemiplegia, $n(\%)$} \\
\hline Right & $10(66.7)$ & $6(40.0)$ & 2.143 & NS \\
\hline Left & $5(33.3)$ & $9(60.0)$ & & \\
\hline \multicolumn{5}{|l|}{ Hemorrhage, $n(\%)$} \\
\hline $\mathrm{ICH}$ & $8(53.3)$ & $4(26.7)$ & 8.133 & NS \\
\hline SAH & $4(26.7)$ & $1(6.7)$ & & \\
\hline SDH & 0 & $1(6.7)$ & & \\
\hline \multicolumn{5}{|l|}{ Infarction, $n(\%)$} \\
\hline MCA & $3(20.0)$ & $6(40.0)$ & & \\
\hline Pontine & 0 & $1(6.7)$ & & \\
\hline BG & 0 & $1(6.7)$ & & \\
\hline Thalamic & 0 & $1(6.7)$ & & \\
\hline Height $(\mathrm{cm})$, mean \pm SD & $166.27 \pm 11.40$ & $162.60 \pm 11.04$ & 0.895 & NS \\
\hline Weight $(\mathrm{kg})$, mean $\pm \mathrm{SD}$ & $62.60 \pm 8.90$ & $58.33 \pm 12.51$ & 1.076 & NS \\
\hline $\mathrm{BMI}\left(\mathrm{kg} / \mathrm{m}^{2}\right)$, mean $\pm \mathrm{SD}$ & $22.72 \pm 2.51$ & $22.36 \pm 3.27$ & 0.338 & NS \\
\hline Months poststroke, mean $\pm \mathrm{SD}$ & $8.64 \pm 2.34$ & $10.23 \pm 3.07$ & -1.595 & NS \\
\hline MMSE-K (score), mean \pm SD & $27.53 \pm 1.95$ & $27.73 \pm 2.60$ & -0.238 & NS \\
\hline Brunnstrom Stages $(2 / 3 / 4)$, mean \pm SD & $2.80 \pm 0.77(6 / 6 / 3)$ & $3.13 \pm 0.83(4 / 5 / 6)$ & -1.134 & NS \\
\hline
\end{tabular}

WBBMWM: Weight-bearing-based mobilization with movement group, NS: Not significant, BMI: Body mass index, MMSE-K: Mini-mental state examination-Korean, ICH: Intracerebral hemorrhage, SAH: Subarachnoid hemorrhage, SDH: Subdural hemorrhage, MCA: Middle cerebral artery, BG: Basal ganglion, SD: Standard deviation

\begin{tabular}{|c|c|c|c|c|c|c|c|c|c|}
\hline \multirow[t]{3}{*}{ Parameters } & \multicolumn{6}{|c|}{ Values } & \multicolumn{3}{|c|}{ Change values } \\
\hline & \multicolumn{3}{|c|}{ WBBMWM $(n=15)$} & \multicolumn{3}{|c|}{ Control $(n=15)$} & \multirow{2}{*}{$\begin{array}{c}\text { WBBMWM } \\
\quad(n=15) \\
\text { Before-after }\end{array}$} & \multirow{2}{*}{$\begin{array}{c}\text { Control } \\
(n=15) \\
\text { Before-after }\end{array}$} & \multirow[t]{2}{*}{$t(P)$} \\
\hline & Before & After & $t(P)$ & Before & After & $t(P)$ & & & \\
\hline$\overline{\text { WBLT }(\mathrm{cm})}$ & $3.20 \pm 2.78$ & $5.80 \pm 3.27$ & $-5.987(0.000)$ & $2.93 \pm 2.89$ & $3.80 \pm 3.36$ & $-2.982(0.010)$ & $2.60 \pm 1.68$ & $0.87 \pm 1.12$ & $3.317(0.003)$ \\
\hline TUG (s) & $27.15 \pm 12.25$ & $21.78 \pm 8.93$ & $35.107(0.000)$ & $24.64 \pm 14.30$ & $22.01 \pm 12.71$ & $3.810(0.002)$ & $-5.37 \pm 4.07$ & $-2.63 \pm 2.68$ & $-2.171(0.039)$ \\
\hline DGI (score) & $15.40 \pm 3.48$ & $19.13 \pm 2.64$ & $4-7.436(0.000)$ & $17.20 \pm 3.57$ & $19.40 \pm 3.54$ & $-5.284(0.000)$ & $3.73 \pm 1.94$ & $2.20 \pm 1.61$ & $2.351(0.026)$ \\
\hline
\end{tabular}


eyes closed, which increased from $3.08 \mathrm{~cm} / \mathrm{s}$ to 2.92 $\mathrm{cm} / \mathrm{s}$ after training $(P=0.013)$ [Table 3$]$.

\section{Discussion}

Active and passive movement restriction on ankle joint is a common disability for stroke patients. ${ }^{[4]}$ Stroke patients have restricted ankle movement compared to normal. ${ }^{[26]}$ These restrictions affect functional movements. ${ }^{[13]}$ Sit to stand and move, gait, and climbing stairs need approximately 30 degrees of ankle joint ROM. ${ }^{[27]}$

This study measured WBLT to compare difference between before and after the ankle joint ROM training exercise. Weight-bearing-based joint mobilization were conducted for 4 weeks, 10 repetitions of 5 sets. As a result, experimental group had remarkable increase from $3.20 \mathrm{~cm}$ to $5.80 \mathrm{~cm}$ and control group had increased from $2.93 \mathrm{~cm}$ to $3.80 \mathrm{~cm}$; thus, there was considerable difference between the two groups $(P<0.05)$.

Decrease of ankle joint dorsiflexion causes restriction of surrounding contractile and noncontractile tissues to interfere with ankle bone gliding. ${ }^{[28]}$ Autonomically combined movement of posterior glide of ankle bone and dorsiflexion of ankle joint affects ankle joint. Ankle joint stretching exercise prevents joint contracture and increases joint $\mathrm{ROM},{ }^{[29]}$ and intermuscle tension. It also stimulates Golgi tendon organs to provoke muscle relaxation, but inhibits muscle spasm; therefore, it is effective on lengthening muscle. ${ }^{[30]}$ Joint mobilization increases flexibility and extensibility of noncontractile tissue surrounding talocrural articulation; $;^{[31]}$ this increases additional movements of ankle joint. ${ }^{[13]}$ Vicenzino et al..$^{[21]}$ defines that weight-bearing based joint mobilization is a type of a manual therapy technique which makes joint sliding consistently backward in ankle joint. Therefore, this study lengthens contractile tissues surrounding ankle joint by weight-bearingbased joint mobilization and posteriorly sliding ankle bone consistently through manual therapy. execution to increase additional movements, and ankle joint ROM through improvement of fl exibility and extensibility in noncontractile tissues are considered.
In this study, TUG is used to measure difference between before and after the dynamic balance training, as a result of weight-bearing-based joint mobilization for 4 weeks 10 repetitions of 5 sets; experiment group had considerable decrease from 27.15 to $21.78 \mathrm{~s}$ which is $5.37 \mathrm{~s}$ difference and control group also had considerable decrease from 24.64 to $22.01 \mathrm{~s}$ which is $2.63 \mathrm{~s}$; thus, there was remarkable difference between the two groups $(P<0.05)$.

$\mathrm{Wu}$ et $a .^{[32]}$ conducted soleus muscles stretching on standing posture for 12 chronic stroke patients, and experimental group's TUG had decrease from 33.7 to $29.1 \mathrm{~s}(P<0.05)$. Shin and Lee (2014) divided the 22 chronic stroke patients to weight-bearing treadmill group and nonweight-bearing treadmill group. As a result, in weight-bearing treadmill group had considerable decrease from 26.57 to $12 \mathrm{~s}$ which is $14.56 \mathrm{~s}$ difference $(P<0.05)$; there was remarkable difference between the two groups $(P<0.05)$. This matches the results of advanced researches and stands for improvement of dynamic balance.

After stroke due to decrease of postural control and muscle weakness on lesion side body dissymmetry is shown, ${ }^{[33]}$ limited ankle ROM decrease movement of center of gravity within the base of support therefore affects the balance. ${ }^{[34]}$ Thus, ankle joint ROM is important to balance. ${ }^{[35]}$ Joint mobilization on stroke patient shown improve of ankle joint ROM, and then, increase of ankle joint ROM improved speed of movement of tibia in ankle joint while standing up. ${ }^{[13]}$ For these reasons, this study is to conduct weight-bearing-based joint mobilization which improves lesion side ankle joint ROM to decrease standing up time which is initiation; improvement of dynamic balance from improvement of dynamic balance is considered.

Gait improvement of stroke patient during function rehabilitation process is a main goal for both patient and therapist; reason is that gait can be an important matter for functional independence. ${ }^{[36]}$ This study used DGI to measure the difference before and after the gait

\begin{tabular}{|c|c|c|c|c|c|c|c|c|c|}
\hline \multirow{4}{*}{ Parameters } & \multirow{2}{*}{\multicolumn{6}{|c|}{ Values }} & \multirow{2}{*}{\multicolumn{3}{|c|}{ Change values }} \\
\hline & & & & & & & & & \\
\hline & \multicolumn{3}{|c|}{ WBMWM $(n=15)$} & \multicolumn{3}{|c|}{ Control $(n=15)$} & \multirow{2}{*}{$\begin{array}{c}\text { WBMWM } \\
\quad(n=15) \\
\text { Before-after }\end{array}$} & \multirow{2}{*}{$\begin{array}{c}\text { Control } \\
(n=15) \\
\text { Before-after }\end{array}$} & \multirow[t]{2}{*}{$t(P)$} \\
\hline & Before & After & $t(P)$ & Before & After & $t(P)$ & & & \\
\hline PSPL/EO $(\mathrm{cm})$ & $43.42 \pm 7.05$ & $37.71 \pm 5.49$ & $6.948(0.000)$ & $41.17 \pm 7.37$ & $38.46 \pm 7.08$ & $3.512(0.003)$ & $-5.70 \pm 3.18$ & $-2.70 \pm 2.98$ & $-2.660(0.013)$ \\
\hline TPSS/EO $(\mathrm{cm} / \mathrm{s})$ & $2.89 \pm 0.47$ & $2.51 \pm 0.36$ & $8.858(0.000)$ & $2.74 \pm 0.49$ & $2.56 \pm 0.47$ & $5.410(0.000)$ & $-0.38 \pm 0.21$ & $-0.17 \pm 0.19$ & $-2.725(0.011)$ \\
\hline PSPL/EC (cm) & $54.40 \pm 12.76$ & $46.66 \pm 11.80$ & $4.823(0.000)$ & $46.21 \pm 8.95$ & $43.90 \pm 8.27$ & $2.850(0.013)$ & $-7.74 \pm 6.21$ & $-2.30 \pm 3.13$ & $-3.022(0.005)$ \\
\hline TPSS/EC $(\mathrm{cm} / \mathrm{s})$ & $3.62 \pm 0.85$ & $3.11 \pm 0.78$ & $4.823(0.000)$ & $3.08 \pm 0.59$ & $2.92 \pm 0.55$ & $2.850(0.013)$ & $-0.51 \pm 0.41$ & $-0.15 \pm 0.20$ & $-3.022(0.005)$ \\
\hline
\end{tabular}


training. DGI is an assessment tool to measure risk of fall and functional safety. ${ }^{[37]}$ In consequence of 4 weeks of 10 repetitions, 10 sets of weight-bearing-based joint mobilization, experimental group had considerable 3.73 score increase from 15.40 to 19.13 , control group had 2.20 score increase from 17.20 to 19.40 ; thus, there was remarkable difference between the two groups $(P<0.05)$.

Weight-bearing training improves sensory information of lower extremity to improve stance period duration. Compensation due to restriction of dorsiflexion on ankle joint is especially shown during middle stance period. ${ }^{[38,39]}$ This restricted ROM interferes posterior glide of tibia during middle stance period, as a result initial stage of heel off strategy cause forward located body. ${ }^{[40]}$ Furthermore, decrease of dorsiflexion on ankle joint causes reduction of weight load on rear-foot during stance period relatively fore-foot weight load increases which decrease ankle rocker during dorsiflexion of ankle joint, ${ }^{[41]}$ during gait limited ankle joint ROM provoke compensation of fast heel off. ${ }^{[42]}$ Yoon et al. ${ }^{[43]}$ conducted weight-bearing-based joint mobilization and got improved in ankle joint ROM and heel off time which showed effectiveness on ankle rocking; Kang et al. ${ }^{[18]}$ conducted weight-bearing-based joint mobilization and reported improvement of ankle joint ROM, heel off time, and dorsiflexion ROM before heel off during stance period.

For these reasons, it is considered that through weight-bearing trainings such as flatland walking and climbing up and down the stairs provoke activation of neuromuscular control of lower body cause gait improvement. Furthermore, applying joint mobilization improved ankle rocking by creating additional movement during stance period; consequently, it is considered that improvement of dorsiflexion ROM before heel off and ankle joint stability cause improvement of gait movement such as rotating using one foot as a pivot during gait, gait over obstacles, weight-bearing on one side, and pivoting.

\section{CONCLUSION}

In this study, WBMWM improved ROM of ankle joint, balance, and gait function in patients with chronic stroke. It is considered that through posterior talar glide and dorsiflexion of the ankle plus MWM improved dorsiflexion, ankle joint stability, and gait movement. Therefore, they are effective training methods for improvement of functional ability and might be used actively in a clinic.

\section{Financial support and sponsorship}

Nil.

\section{Conflicts of interest}

There are no conflicts of interest.

\section{REFERENCES}

1. Susan B, Thomas J. Physical Rehabilitation: Assessment and Treatment. Philadelphia: FA Davis; 2001.

2. Mahabir D, Bickram L, Gulliford MC. Stroke in Trinidad and Tobago: Burden of illness and risk factors. Rev Panam Salud Publica 1998;4:233-7.

3. Sharp SA, Brouwer BJ. Isokinetic strength training of the hemiparetic knee: Effects on function and spasticity. Arch Phys Med Rehabil 1997;78:1231-6.

4. Given JD, Dewald JP, Rymer WZ. Joint dependent passive stiffness in paretic and contralateral limbs of spastic patients with hemiparetic stroke. J Neurol Neurosurg Psychiatry 1995;59:271-9.

5. Srivastava A, Taly AB, Gupta A, Kumar S, Murali T. Post-stroke balance training: Role of force platform with visual feedback technique. J Neurol Sci 2009;287:89-93.

6. Geiger RA, Allen JB, O'Keefe J, Hicks RR. Balance and mobility following stroke: Effects of physical therapy interventions with and without biofeedback/forceplate training. Phys Ther 2001;81:995-1005.

7. Wolfson L, Whipple R, Judge J, Amerman P, Derby C, King M, et al. Training balance and strength in the elderly to improve function. J Am Geriatr Soc 1993;41:341-3.

8. Granat MH, Maxwell DJ, Ferguson AC, Lees KR, Barbenel JC. Peroneal stimulator; evaluation for the correction of spastic drop foot in hemiplegia. Arch Phys Med Rehabil 1996;77:19-24.

9. Perry J, Garrett M, Gronley JK, Mulroy SJ. Classification of walking handicap in the stroke population. Stroke 1995;26:982-9.

10. Hwang DY, Lee HJ, Lee GC, Lee SM. Treadmill training with tilt sensor functional electrical stimulation for improving balance, gait, and muscle architecture of tibialis anterior of survivors with chronic stroke: A randomized controlled trial. Technol Health Care 2015;23:443-52.

11. Daher N, Lee S, Yang YJ. Effects of elastic band orthosis (aider) on balance and gait in chronic stroke patients. Phys Ther Rehabil Sci 2013;2:81-6.

12. Park YH, Kim YM, Lee BH. An ankle proprioceptive control program improves balance, gait ability of chronic stroke patients. J Phys Ther Sci 2013;25:1321-4.

13. Kluding PM, Santos M. Effects of ankle joint mobilizations in adults poststroke: A pilot study. Arch Phys Med Rehabil 2008;89:449-56.

14. Green T, Refshauge K, Crosbie J, Adams R. A randomized controlled trial of a passive accessory joint mobilization on acute ankle inversion sprains. Phys Ther 2001;81:984-94.

15. Mulligan BR. Mobilisations with movement (MWM'S). J Man Manip Ther 1993;1:154-6.

16. Reid A, Birmingham TB, Alcock G. Efficacy of mobilization with movement for patients with limited dorsiflexion after ankle sprain: A crossover trial. Physiother Can 2007;59:166-72.

17. Marrón-Gómez D, Rodríguez-Fernández ÁL, Martín-Urrialde JA. The effect of two mobilization techniques on dorsiflexion in people with chronic ankle instability. Phys Ther Sport 2015;16:10-5.

18. Kang MH, Kim JW, Choung SD, Park KN, Kwon OY, Oh JS, et al. Immediate effect of walking with talus-stabilizing taping on ankle kinematics in subjects with limited ankle dorsiflexion. Phys Ther Sport 2014;15:156-61. 
19. Maitland G. Peripheral Manipulation. $3^{\text {rd }}$ ed. London: Butterworth-Heinemann; 1991.

20. Collins N, Teys P, Vicenzino B. The initial effects of a mulligan's mobilization with movement technique on dorsiflexion and pain in subacute ankle sprains. Man Ther 2004;9:77-82.

21. Vicenzino B, Branjerdporn M, Teys P, Jordan K. Initial changes in posterior talar glide and dorsiflexion of the ankle after mobilization with movement in individuals with recurrent ankle sprain. J Orthop Sports Phys Ther 2006;36:464-71.

22. Beazell JR, Grindstaff TL, Sauer LD, Magrum EM, Ingersoll CD, Hertel $\mathrm{J}$, et al. Effects of a proximal or distal tibiofibular joint manipulation on ankle range of motion and functional outcomes in individuals with chronic ankle instability. J Orthop Sports Phys Ther 2012;42:125-34.

23. Bennell KL, Talbot RC, Wajswelner H, Techovanich W, Kelly DH, Hall AJ, et al. Intra-rater and inter-rater reliability of a weight-bearing lunge measure of ankle dorsiflexion. Aust J Physiother 1998;44:175-80.

24. Kim N, Park Y, Lee BH. Effects of community-based virtual reality treadmill training on balance ability in patients with chronic stroke. J Phys Ther Sci 2015;27:655-8.

25. Ng SS, Hui-Chan $\mathrm{CW}$. The timed up and amp; go test: Its reliability and association with lower-limb impairments and locomotor capacities in people with chronic stroke. Arch Phys Med Rehabil 2005;86:1641-7.

26. Chung SG, Van Rey E, Bai Z, Roth EJ, Zhang LQ. Biomechanic changes in passive properties of hemiplegic ankles with spastic hypertonia. Arch Phys Med Rehabil 2004;85:1638-46.

27. Wu G. A review of body segmental displacement, velocity, and acceleration in human gait. In: Craik RL, Oatis CA, editors. Gait Analysis: Theory and Application. St. Louis, MO, USA: Mosby; 1995. p. 205-22.

28. Hertel J. Functional anatomy, pathomechanics, and pathophysiology of lateral ankle instability. J Athl Train 2002;37:364-75.

29. Bohannon RW, Larkin PA. Passive ankle dorsiflexion increases in patients after a regimen of tilt table-wedge board standing. A clinical report. Phys Ther 1985;65:1676-8.

30. Sahin N, Ugurlu H, Karahan AY. Efficacy of therapeutic ultrasound in the treatment of spasticity: A randomized controlled study. NeuroRehabilitation 2011;29:61-6.

31. Hoch MC, Andreatta RD, Mullineaux DR, English RA, Medina McKeon JM, Mattacola CG, et al. Two-week joint mobilization intervention improves self-reported function, range of motion, and dynamic balance in those with chronic ankle instability. J Orthop Res 2012;30:1798-804.

32. $\mathrm{Wu} \mathrm{CL}$, Huang $\mathrm{MH}$, Lee $\mathrm{CL}$, Liu $\mathrm{CW}$, Lin LJ, Chen $\mathrm{CH}$, et al. Effect on spasticity after performance of dynamic-repeated-passive ankle joint motion exercise in chronic stroke patients. Kaohsiung J Med Sci 2006;22:610-7.

33. Chou SW, Wong AM, Leong CP, Hong WS, Tang FT, Lin TH, et al. Postural control during sit-to stand and gait in stroke patients. Am J Phys Med Rehabil 2003;82:42-7.

34. Spink MJ, Fotoohabadi MR, Wee E, Hill KD, Lord SR, Menz HB, et al. Foot and ankle strength, range of motion, posture, and deformity are associated with balance and functiona ability in older adults. Arch Phys Med Rehabil 2011;92:68-75.

35. Vaillant J, Rouland A, Martigné P, Braujou R, Nissen MJ, Caillat-Miousse $\mathrm{JL}$, et al. Massage and mobilization of the feet and ankles in elderly adults: Effect on clinical balance performance. Man Ther 2009;14:661-4.

36. Turnbull GI, Charteris J, Wall JC. A comparison of the range of walking speeds between normal and hemiplegic subjects. Scand J Rehabil Med 1995;27:175-82.

37. Shumway-Cook A, Woollacott MH. Motor control: Theory and practical applications. Baltimore: Lippincott Williams \& Wilkins; 1995.

38. Johanson MA, Cuda BJ, Koontz JE, Stell JC, Abelew TA. Effect of stretching on ankle and knee angles and gastrocnemius activity during the stance phase of gait. J Sport Rehabil 2009;18:521-34

39. Drewes LK, McKeon PO, Kerrigan DC, Hertel J. Dorsiflexion deficit during jogging with chronic ankle instability. J Sci Med Sport 2009;12:685-7.

40. Perry J, Burnfield M. Gait Analysis. $2^{\text {nd }}$ ed. New Jersey: Slack Inc.; 2010.

41. Selby-Silverstein L, Farrett WD Jr., Maurer BT, Hillstrom HJ. Gait analysis and bivalved serial casting of an athlete with shortened gastrocnemius muscles: A single case design. J Orthop Sports Phys Ther 1997;25:282-8.

42. Aronow MS, Diaz-Doran V, Sullivan RJ, Adams DJ. The effect of triceps surae contracture force on plantar foot pressure distribution. Foot Ankle Int 2006;27:43-52.

43. Yoon JY, Hwang YI, An DH, Oh JS. Changes in kinetic, kinematic, and temporal parameters of walking in people with limited ankle dorsiflexion: Pre-post application of modified mobilization with movement using talus glide taping. J Manipulative Physiol Ther 2014;37:320-5. 